Una mirada

histórica

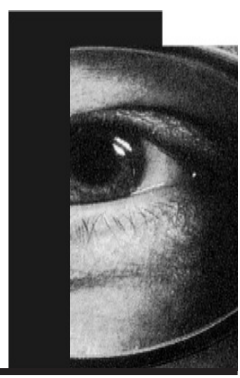

\title{
ALCOHOLISMO EN LAS TESIS DE LA FACULTAD DE CIENCIAS MÉDICAS DE CÓRDOBA A FINES DEL SIGLO XIX
}

ALCOHOLISM IN THESES FROM THE SCHOOL OF MEDICINE OF CORDOBA AT THE END OF THE 19TH CENTURY.

ALCOOLISMO NAS TESES DA FACULDADE DE CIÊNCIAS MÉDICAS DE CÓRDOBA NO FINAL DO SÉCULO

\section{Resumen:}

Nos introducimos a analizar un conjunto de Tesis de la Facultad de Ciencias Médicas de la Universidad Nacional de Córdoba entre fines del siglo XIX y primeros años del XX, para estudiar a partir de ellas cómo el naciente campo de la psiquiatría conformó discursos alrededor del alcoholismo. Complejizamos aquellas lecturas dominantes hasta el momento en la historiografía local que hablan de unas tramas discursivas y de unos saberes en la psiquiatría y la medicina legal cordobesa definidos por el preeminente influjo del catolicismo vernáculo.

Palabras Clave: Psiquiatría, medicina legal, Córdoba, alcoholismo, mala vida, moral.

\section{Abstract:}

We began to analyze a set of Theses from the School of Medicine of the National University of Cordoba dated between the end of the 19th century and the beginning of 
the 20th as a starting point to study how the emerging field of psychiatry defined speech around alcoholism. We sophisticated the controlling readings up to that moment in the local historiography referring to narrative plots and knowledge in psychiatry and legal medicine from Cordoba defined by the preeminent influence of vernacular catholicism.

Key words: Psychiatry, Legal medicine, Cordoba, Alcoholism, Bad life, Moral.

\section{Resumo:}

$\mathrm{O}$ alvo da nossa pesquisa foi analisar um conjunto de Teses da Faculdade de Ciências Médicas da Universidade Nacional de Córdoba entre o final do século XIX e os primeiros anos do vigésimo, para estudar como o campo nascente da psiquiatria formou discursos em torno do alcoolismo. Analizaram-se aquelas leituras dominantes até o momento na historiografia local que fala de enredos discursivos e dos conhecimentos na psiquiatria e medicina legal cordobesa definida pelo preeminente pela influência do catolicismo vernáculo.

Palavras Chave: Psiquiatria, medicina legal, Córdoba, alcoolismo, vida ruim, moral.

\section{Introducción}

En el actual trabajo abordamos un conjunto de trabajos finales de medicina para ensayar algunas preguntas acerca de la articulación de saberes y discursos sobre el alcoholismo durante los momentos iníciales en la estructuración del campo de la psiquiatría en la Facultad de Ciencias Médicas de la Universidad Nacional de Córdoba. Como ya es usual en la práctica historiográfica local que viene estudiando este tipo de entramados locales, también nosotros nos preguntamos si las ideas que circulaban localmente constituían sólo una especie de continuidad de las nociones porteñas e internacionales, o si, es posible dar cuenta de cierta especificidad "cordobesa".

Consideramos que las lecturas predominantes han mantenido cierta simplificación en sus interpretaciones sobre los discurso y los saberes de la medicina y, en este caso específico refiriéndonos a la psiquiatría y la criminología y sus conceptualizaciones de las desviaciones de los comportamientos individuales y sociales entre finales del siglo XIX y primeros años del XX (1). Procuramos plantear que no es viable seguir validando las argumentaciones que hasta el momento han intentado mostrar que en la academia de Córdoba se articularon discursos y saberes alrededor del alcoholismo y de "mala vida" caracterizados por un predominio de categorías morales ligadas a lo católico-conservador (2). No tratamos de negar que la modernización de la Argentina tuvo itinerarios heterogéneos y, entre ellos, los del interior nacional se identificaron en gran medida por el peso superlativo del componente tradicional, ampliamente reconocido como conservador y católico en Córdoba. Una aproximación inicial a nuestras fuentes de época, da cuenta de un proceso de configuración de los discursos-saberes de la medicina mental y legal proclive -ya desde los primeros trabajos universitarios locales- a entramar nociones e interpretaciones científicas en boga por aquellos años. Nos introducirnos en esta complejidad recorriendo suscintamente los discursos locales analizando cómo los tesistas médicos conceptualizaron la problemática del alcoholismo enfatizando en argumentos ligados a la herencia y a determinismos sociales y biológicos propios de una lógica fatalista positivista que orientó la perspectiva moral según un evidente sesgo de clase.

\section{El alcoholismo, entre la enfermedad y la moral (¿católica?)}

Qué significa sostener, como ha señalado el análisis de Ana Clarisa Agüero, que en los discursos de la medicina de Córdoba las nociones sobre el alcoholismo y los sujetos alco- 
hólicos estaban constreñidos por el campo clerical, “(...) antimaterialista...que invocaba en menor grado que rechazaba la instalación de la ciencia como paradigma" (3). Detengámonos en una de las mayores confusiones presentes en este tipo de lecturas que asocian la moralidad de las categorías médicas al influjo del catolicismo: para Agüero “(...) si algo caracteriza al discurso médico local es el lento ritmo de su despojamiento de categorías morales en favor de un lenguaje de lo físico" (4). Debemos tener presente que, si bien es incuestionable la presencia de los actores católicos en la asistencia sanitaria y con ella también la dedicada a lo mental en Córdoba, ello no habilita a plantear que una elite médica que buscaba por estos años consolidarse construyendo su monopolio cognitivo y de la práctica especializada abrazara nociones religiosas.

Constituye un punto clave la lectura de Campos y Huertas sobre el discurso médico en España a partir del último cuarto del siglo XIX. Según ellos, la peculiar forma de "enfermar" del alcoholismo, a través de la ingestión voluntaria, ayudó a configurar un discurso en el que primó lo moral, la idea de vicio y voluntariedad (5). Siguiendo esa impronta, explican los autores, se moralizaron las nociones de época y, aún luego de haberse definido en 1852 al alcoholismo como una entidad nosológica diferenciada (según los aportes de Magnus Huss), médicos y psiquiatras europeos y españoles continuaron utilizando de manera aleatoria los conceptos de "vicio" y de "enfermedad". Entonces, desde esa mirada es posible interpretar que las tesis de medicina presentadas entre fines del siglo XIX y principios en la Facultad de Ciencias Médicas de la UNC proponen lecturas "morales" de los comportamientos. Urtubey (1884) refirió a la acción del alcohol sobre el organismo explicando que,

Una vez que el individuo ha llegado a ese estado, el individuo que era laborioso, activo.... Dominado por su pasión, se hace indolente para consigo mismo y para con su familia, pierde su dignidad, su inteligencia, su memoria, y se convierte en un degradado, miserable, y crápula, por este vicio degradante (6).

Verificamos la vigencia de estas interpretaciones atravesando los límites del siglo XIX. Del Carril también habló del alcoholismo como un vicio que ataca por su base al orgaismo social ..." (7) Galíndez, ya para 1905, insistió en que el alcoholismo constituye "la más común de las enfermedades y el más pernicioso de los vicios" (8). Esta misma lógica que subyace a la idea del alcoholismo como vicio puso sobre el tapete la idea moral de hábito pernicioso, donde entraba en juego la voluntad del individuo. Tal como los psiquiatras franceses del siglo XIX, en el caso local, la voluntad tuvo un lugar clave en todo el asunto. La influencia francesa se hizo evidente en el mapa cordobés. Tal como refirió Esquirol en 1838, asociando la necesidad de ingerir alcohol a la generación de una "lesión de la volonté", el tesista cordobés Del Carril señaló que (...) "la voluntad se pervierte y la falta de ella es una de los rasgos más característicos del alcoholizado (...) él que como la inteligencia aún conserva su integridad (...) comprende sus derechos y obligaciones, pero le falta la fuerza de voluntad necesaria para efectuarlos" (9).

Debemos ser muy cautos en cómo interpretar estas nociones, sin perder de vista que las mismas constituyen una especie de punta de iceberg de asuntos más complejos a determinar, cómo los que concernían a la responsabilidad del alcohólico por sus actos fuera de la norma social bajo los efectos de la bebida. En las tesis de la Facultad de Ciencias Médicas de Córdoba -como era usual en los trabajos médicos elaborados en Europa o en Buenos Aires (10)- fue una práctica dominante asociar al alcoholismo a la vagancia, los disturbios del orden público y, en particular a los comportamientos asociados a la denominada "mala vida", es decir, las conductas ubicadas en una zona intermedia entre locura y delito (11). Para fines del siglo XIX los trabajos locales dirán que "la embriaguez figura como una de las causas que con más frecuencia interviene en la producción de la locura. Entre nosotros más el 30 por ciento de los alienados reconocen por causa el alcoholismo" (12), mientras 
"las 2/3s partes de los asesinatos de los atentados a las costumbres, rebeliones, violencias, suicidios ....son producidos por el alcoholismo" (13). Como se puede apreciar, los médicos hacían constantes referencias a las estadísticas como fuente de datos e instrumentos de fundamentación científica. Luego, a medida que avancemos en el siglo XX, tales herramientas serán una constante central en los trabajos académicos. Lo sugerente a considerar es que las preocupaciones académicas de estos tesistas, pueden definirse alrededor del interés por analizar y catalogar la marginalidad urbana que se consideraba consecuencia de la modernidad de época (14). Para esa época se estaba frente a una Córdoba altamente favorecida por la llegada del ferrocarril, que, como nudo troncal del sistema ferroviario devino prontamente en especio de instalación de empresas vinculadas a ésta actividad como talleres, fábricas y oficinas (15).

Ante este escenario de cambios y preocupaciones por la modernidad, una vez más debemos ser cautos en nuestros análisis. Aunque nuestros médicos puedan definirse como actores de saber/poder, integrantes de una elite que comenzaba a formar parte del aparato estatal y del proyecto de control social de la época, ciertos renglones de su agenda nos llevan a matizar las lecturas. Desde el siglo XIX, los tesistas locales que estudiaban los diversos periodos de alcoholismo, sostuvieron que un alcohólico, aunque haya roto las pautas sociales -de evidente raigambre burguesa- podía ser eximido de su responsabilidad ante esa misma sociedad damnificada. Es que, según se desprende de los trabajos analizados, aquella mixtura de nociones en torno al alcoholismo como enfermedad y a la vez como conducta moral, favoreció explicaciones como las de Urtubey que sostenían que "un enfermo en este estado puede cometer crímenes, sin tener conciencia de los que ha hecho por tanto es necesario que el médico legista lo exonere de los cargos" (16).

También Del Carril dejó en evidencia que, mientras se daba un proceso de consolidación de la especialidad, aún incipiente en estos años, ello no iba en sentido contrario a sostener que casi cualquiera que haya cometido un delito luego de haber ingerido alcohol podía ser no responsable de su conducta:

(...) gran número de actos criminales producidos por individuos en estado de ebriedad, son debidos indudablemente verdaderos actos de locura transitoria y el medico es llamado con frecuencia a deslindar la parte de responsabilidad que corresponde al actor (17).

No pretendemos dar cuenta de posibles rupturas o debates entre las ideas del derecho y la medicina, pero no podemos soslayar que en la naciente criminología moderna de Córdoba, uno de sus más conspicuos representantes, Cornelio Moyano Gacitúa insistió para fines del siglo XIX y primeros años del XX en la idea de libre albedrío, "según la cual los individuos se caracterizan, ante todo, por su capacidad de decisión y creatividad que es imposible de explorar" (18). Es relevante desterrar la idea que sostiene Ferrari al hablar del discurso de la criminología local postulando que “(...) el positivismo encontró sus adversarios en la ciudad mediterránea al introducirse en el espacio de la moral" [porque el planteo era] "(...) sin libre albedrío el pecado no era pecado y la virtud no era virtud” (19). En realidad, Gacitúa se destacó por su actitud científica (20) que amalgama nociones de diversa índole y, en ese marco, la disputa entre determinismo y libre albedrío se enmarcó en la supervivencia de teorías y postulados del Derecho Penal Clásico, en tiempos de cimentación de la Escuela Penal Positiva, (el Derecho Penal Clásico exigía apartar elementos extrajurídicos, es decir morales y religiosos) (21). Según esta matriz, es comprensible que Moyano en su curso de ciencia criminal sentenciara que raramente el alcoholismo era un atenuante de la responsabilidad, ya que,

(...) como ese estado puede ser producido voluntariamente, y como en él es posible y según los caracteres del sujeto que bebe es inminente la comisión 
de delitos, la ley no puede menos que tener en cuenta la imprudencia que comete en el que se pone en ese estado, para atribuirle las responsabilidades consiguientes en caso de delito (22).

En este punto lo más notable de su "heterodoxa filiación positivista", fue su rechazo al determinismo biológico, por lo que el factor de la herencia de Lombroso es vista como una exageración (23). Este será su contrapunto más significativo con las lecturas de los tesistas cordobeses que, desde fines del siglo XIX, enfatizaron en entramados vinculados a la herencia y a determinismos sociales y biológicos propios de la lógica fatalista de las explicaciones positivistas. El alcoholismo es "una enfermedad de la familia" ya que esta "probado que los hábitos alcohólicos de los padres dan a la generación cierto tipo especial constituido por degeneración física o psíquica..." (24). Desde esta impronta, el alcoholismo va conformándose en enfermedad social, jalonada en su conceptualización por factores que vincularon la "degeneración reproductiva" a un sesgo de clase social. A esta altura, aunque supera los límites de este breve estudio, vale destacar quepara nuestra elite médica los (...) hijos de los bebedores" eran... física y moralmente degenerados" (25) y esta tendencia no era igual en cualquier sector social, ya quese defendía que "el pobre se embriaga más o menos periódicamente y da escándalo público y privado...[en]... la clase obrera ...el mal ha echado profundas raíces; no menos de un $70 \%$ de entre ellos, se entrega de lleno al dios del Baco" (26).

\section{Conclusiones:}

A pesar de haber articulado un primer análisis, las problemáticas consideradas abren todo un panorama a indagar. Nuestros próximos estudios deben profundizar en un escenario complejo, donde la medicina ejerció un papel clave en el empeño para usar racionalmente a los trabajadores en el marco de un sistema capitalista dependiente y, esos impulsos tuvieron un sesgo eminentemente moral, no identificado necesariamente con el ideario católico. Pero hay que ser prudentes, ya que la psiquiatría y sus especialistas fueron mucho más que eso. La construcción de la agenda de saberes y los procesos de consolidación profesional no constituyen fenómenos marginales de esta historia. En próximos análisis pondremos en perspectiva cómo los trabajos médicos fueron definiendo las causas sociales del alcoholismo, ellas, aparecieron junto a otras de diversa naturaleza, como las relacionadas con la influencia del clima o incluso la falta de moral cristiana. Mostraremos que, a pesar de que el alcoholismo era construido como una enfermedad social, de causas también sociales ancladas en la desigualdad, la gran mayoría de las propuestas médicas para dar respuesta al flagelo, se definieron centradas en el individuo como tal, los problemas sociales eran vistos más bien como síntomas que recibían atención concreta preferentemente cuando la "cuestión social" devenía en un problema de y para el orden y el progreso nacional, de gobernabilidad para las elites.

\section{Bibliografía:}

1) Dovio M. El caso de la "mala vida", peligrosidad y prevención de conductas marginales. Revista de Criminología, Psiquiatría, Medicina Legal y Ciencias Afines, en Buenos Aires, 1914-1923. História, Ciências, Saúde - Manguinhos. 2013; 20:13: 1225. Disponible en: http://www.scielo.br/pdf/hcsm/v20s1/0104-5970-hcsm20-s-1224.pdf ; [consultado el 10/04/2016]

2) Agüero A C. Alcoholismo y "cuestión social". Sobre hegemonía discursiva en el cambio de siglo. (Córdoba 1880-1914). [Tesis para obtener la Lic. En Historia]. Facultad de Filosofía y Humanidades Universidad Nacional de Córdoba: 2001. 19. Agüero A C. Alcoholismo y "cuestión social". Sobre hegemonía discursiva en el 
cambio de siglo. Op cit. 17.

4) Agüero A C. Alcoholismo y "cuestión social". Sobre hegemonía discursiva en el cambio de siglo. Op cit. 18.

5) Campos R, Huertas R. El alcoholismo como enfermedad social en la España de la Restauración: probelmas de definción. Dymanis. 1991; (11): 263.

6) Urtubey B. Del Alcohol. [Tesis para obtener el gardo de doctor en Medicina y Cirugía] Facultad de Ciencias Médicas Universidad Nacional de Córdoba; 1884. 53.

7) Del Carril F. Alcoholismo y Locuras Alcóholicas. [Tesis para obtener el grado de doctor en Medicina y Cirugía] Facultad de Ciencias Médicas Universidad Nacional de Córdoba; 1896. 6.

8) Galíndez B. El Alcoholismo. [Tesis para obtener el grado de doctor en Medicina y Cirugía] Facultad de Ciencias Médicas Universidad Nacional de Córdoba; 1905. 15.

9) Del Carril F. Alcoholismo y Locuras Alcóholicas. Op cit. 29.

10) Armus D. La ciudad Impura. Salud, tuberculosis y cultura en Buenos Aires, 18701950. Buenos Aires Argentina: Edhasa; 2007. p. 181-182.

11) Dovio M. História, Ciências, Saúde - Manguinhos. Op cit.

12) Del Carril F. Alcoholismo y Locuras Alcóholicas. Op cit. 11.

13) Urtubey B. Del Alcohol. Op cit. 53.

14) Agüero A C. Alcoholismo y "cuestión social". Op cit.

15) Boixadós M C, Gabetta E. Crecimiento urbano y transacciones inmobiliarias. El caso de la ciudad de Córdoba entre 1880/90. Revista de Economía y Estadística. 1985; 26:77. Disponible en: http://revistas.unc.edu.ar/index.php/REyE/article/ view/3753[consultado el 21/05/2017]

16) Urtubey B. Del Alcohol. Op cit. 53.

17) Del Carril F. Alcoholismo y Locuras Alcóholicas. Op cit. 45.

18) Núñez J A, Cesano J D. La delincuencia argentina ante algunas cifras y teorías. Córdoba Argentina: Buena Vista; 2012. 17.

19) Ferrari J F. Entre el dispositivo psiquiátrico y la monacal: una historiografía genealógica de las primeras lecturas de la psicopatología freudiana en Córdoba (1758-1930). [Tesis para obtener el gardo de doctor Psicología] Facultad de Psicología Universidad Nacional de Córdoba; 2012. 224.

20) Núñez J A, Cesano J D. La delincuencia argentina ante algunas cifras y teorías. Op cit. 44.

21) Milena L. Las ideas penitenciaras en el campo jurídico cordobés. 1885-1911. Anuario de la escuela de Historia Virtual. 2013; 26: 77. Disponible en: http://publicaciones.ffyh.unc.edu.ar/index.php/anuariohistoria [consultado el 12/06/2017]

22) Moyano Gacitúa C. Curso de Ciencia Criminal y Derecho Penal argentino. Buenos Aires: Félix Lajouane: 1899. 44.

23) Moyano Gacitúa C. Curso de Ciencia Criminal y Derecho Penal argentino. Op cit. 91.

24) Del Carril F. Alcoholismo y Locuras Alcóholicas. Op cit. 6.

25) Trucchi E. El Alcohol como alimento, como medicamneto y como veneno. [Tesis para obtener el gardo de doctor en Medicina y Cirugía] Facultad de Ciencias Médicas Universidad Nacional de Córdoba; 1906. 49.

26) Galíndez B. El Alcoholismo. Op cit. 24. 